\title{
In silico analysis of mismatches in RT-qPCR assays of 177 SARS-CoV-2 sequences from Brazil
}

\author{
Renan da Silva Santos ${ }^{[1]}$, Raissa Souza Caminha Bret ${ }^{[1],}$ \\ Ana Cristina de Oliveira Monteiro Moreira ${ }^{[1]}$, Adriana Rolim Campos ${ }^{[1]}$, \\ Angelo Roncalli Alves e Silva ${ }^{[1]}$, Danielle Malta Lima ${ }^{[1]}$ e Kaio Cesar Simiano Tavares ${ }^{[1]}$
}

[1]. Universidade de Fortaleza, Núcleo de Biologia Experimental (NUBEX), Fortaleza, CE, Brasil

\begin{abstract}
Introduction: Quantitative reverse transcription polymerase chain reaction (RT-qPCR) can detect the severe acute respiratory syndrome Coronavirus-2 (SARS-CoV-2) in a highly specific manner. However, a decrease in the specificity of PCR assays for their targets may lead to false negative results. Methods: Here, 177 high-coverage complete SARS-CoV-2 genome sequences from 13 Brazilian states were aligned with 15 WHO recommended PCR assays. Results: Only 3 of the 15 completely aligned to all Brazilian sequences. Ten assays had mismatches in up to 3 sequences and two in many sequences. Conclusion: These results should be taken into consideration when using PCR-based diagnostics in Brazil.
\end{abstract}

Keywords: SARS-CoV-2. COVID-19. Polymerase chain reaction. Diagnosis. Mismatches.

Coronavirus disease 2019 (COVID-19) is a severe acute respiratory syndrome (SARS) caused by the new SARS Coronavirus-2 (SARS-CoV-2, previously known as 2019-nCoV) ${ }^{1}$. COVID-19 exhibits a wide range of symptoms, such as fever, cough, shortness of breath or difficulty breathing, repeated shaking with chills, muscle pain, headache, sore throat, and new loss of taste or smell $^{2}$. While some patients may not develop all of the symptoms, others might experience symptoms not mentioned in the previous list ${ }^{2}$. The outbreak started in Wuhan, China, in December 2019, followed by a rapid and massive worldwide spread, which led to the current pandemic ${ }^{1}$. The pandemic reached Brazil in March 2020; nevertheless, it has caused 2,442,375 confirmed cases and 87,618 confirmed deaths as of July $27,2020^{3}$.

Several assays can be used to diagnose a patient with COVID-19. The polymerase chain reaction (PCR) technique is a molecular assay capable of detecting SARS-CoV-2 viral RNA with high specificity during the acute phase of infection. A wide variety

\footnotetext{
Corresponding author: Kaio Cesar Simiano Tavares

e-mail: kaio@unifor.br

(iD) https://orcid.org/0000-0003-3919-161X

Received 25 September 2020

Accepted 28 October 2020
}

of primers and probes were developed to detect this virus, mainly targeting the following genomic regions: ORF1ab, envelope genes (E), RNA-dependent RNA polymerase (RdRP), spike protein (S), and nucleocapsid $(\mathrm{N})^{4}$. The high specificity of these molecular assays is directly related to the annealing specificity of the primer/probe to the genomic region. The World Health Organization (WHO) has recommended 26 primers and probes to be used in this type of diagnosis ${ }^{5}$.

Recent studies have shown that the rate and pattern of mutations in the SARS-CoV-2 genome differ depending on environmental conditions ${ }^{6}$. The present study investigated the specificity of fifteen primer and probe sets recommended by the WHO in 177 SARS-CoV-2 Brazilian genomes.

The SARS-CoV-2 genome sequences were obtained from the Global Initiative on Sharing Avian Influenza Data-EpiCoV (GISAID-EpiCoV) platform (https://www.gisaid.org/) ${ }^{7}$, an initiative for sharing genetic data of the SARS-CoV-2 virus. Only sequences submitted up to July 27, 2020, and complete genomes (above $29,000 \mathrm{bp}$ ) were included. A high coverage filter was applied, which means that only entries with less than $1 \%$ of undefined bases (stretches of NNNs) were tolerated, and Brazil was used as the location. The selected sequences were downloaded in FASTA format (Supplementary Data S1) and aligned using the ClustalW 
Multiple Alignment ${ }^{8}$ tool of the BioEdit biological sequence editor 7.2.6 $6^{21}$. The genome used as reference was the first strain identified in Wuhan (China) (GenBank: NC_045512.2).

Nucleotide sequences with incomplete specificity of bases and constructions for nested PCR were not included, therefore some constructions were not taken into account in the analysis. The fifteen primers and probes constructions used here (sequences depicted at Figure 1) are recommended for the diagnosis of COVID-19 through RT-qPCR by the World Health Organization (WHO) and were originally available and published by independent institutions in seven countries ${ }^{1,5}$ : China, France, USA, Japan, Germany, Hong Kong, and Thailand. All primers and probes were searched against the aligned genomes.

A total of 177 SARS-CoV-2 complete genome sequences from Brazil, deposited before July 27, 2020, were obtained from GISAID-EpiCoV, and 470 strings were discarded as they did not achieve the requirement for high sequencing coverage. As shown in Figure 1, there are primers and probes with $100 \%$ hybridization against all sequences. However, many show with matching errors. For the N gene (Figure 1A), the Japanese PCR assay, NIID_2019nCOV_N, showed $100 \%$ identity with the aligned sequences. However, most of the diagnostic assays recommended by WHO presented mismatches with the Brazilian SARS-CoV-2 sequences. The German Corman-N, Japanese N_Sarbeco, North American 2019-nCoV_N (N1, N2, and N3), and Thai NIH-TH N presented 1 to 3 base pairs (bp) mismatches. The Chinese assays CN-CDC-N and HKU-N had a high frequency of mismatched sequences, 151 and 101, respectively, in view of the high prevalence of G28881A, G28882A, G28883C, and T29148C mutations. Unlike the mismatches found for the $\mathrm{N}$ gene, the targets against ORF1ab (Figure 1B) and E (Figure 1C) showed less frequent variability. The French nCoV_IP4 and Chinese CN-CDC-E assays demonstrated total identity to their motives. The other assays, nCoV_IP2, CN-

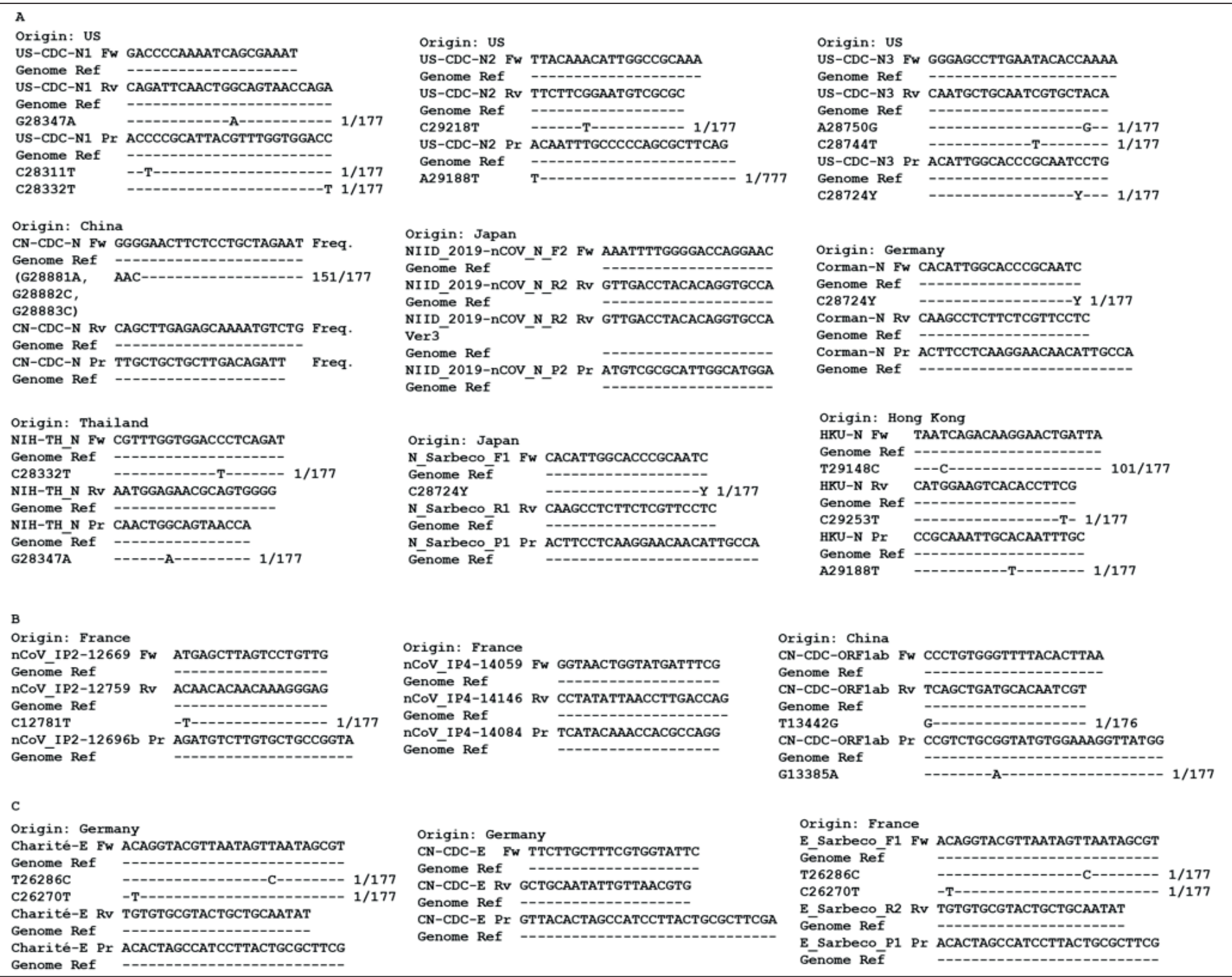

FIGURE 1: Alignment of PCR assays against the reference genome sequence (Genome Ref) and the mutated motifs. The occurrence of mismatch is indicated for each primer, forward (Fw) and reverse (Rv), and probe (Pr) for targets $N(A)$, ORF1ab (B), and E (C). The frequency of a mutation among the 177 aligned sequences is shown on the side, if present. 
CDC-ORF1ab, Charité-E, and E_Sarbeco showed low frequency of errors, such as 1 to $2 \mathrm{bp}$ mismatches.

Thirteen out of the 26 Brazilian states contributed with the deposit of sequences until the collection date. Most of these sequences were from two states, Rio de Janeiro (RJ) $49.71 \%$ (88/177) and São Paulo (SP) 27.69\% (49/177) (Figure 2A). Three of the four most frequent mutations found, G28881A, G28882A, and $\mathrm{G} 28883 \mathrm{C}$, were observed mainly in sequences from RJ (54.30 $\%$ ) and SP (26.49\%) (Figure 2B). However, interestingly, the T29148C mutation was highly common among sequences collected from RJ $(74.25 \%)$ and was rarely seen in the sequences collected in SP (3.96 \%) (Figure 2C). The remaining eleven states had less participation in the number of genomes deposited so far.

Several factors can interfere with the quality of a PCR analysis, and the perfect nucleotide identity match in primers/probes could be a determinant for successful amplification ${ }^{9}$. Our results reveal a total hybridization of PCR assays NIID_2019-nCOV_N, $\mathrm{nCoV}$ IP4, and CN-CDC-E with all aligned sequences. In contrast, the assay devised by the US CDC, 2019-nCoV N3 as well as the German Corman-N and the Japanese N_Sarbeco assays, for N gene hybridization, presented mismatches at a 5 bp distance of their 3' end (Table 1). Base pairing errors in this region can be extremely harmful and directly affect amplification by increasing, on average, by 5 the cycle threshold $(\mathrm{Ct})$ of a PCR analysis, which is a risk factor for a false-negative result $t^{10,11}$.

The assays 2019-nCoV (N1,N2, and N3), NIH-TH_N, nCoV_IP2, CN-CDC-ORF1ab, Charité-E, and E_Sarbeco, presented mismatches located in the 5 ' or central portion of their primers when aligned with the Brazilian viral genomes (Table 1). Although little information is known regarding the influence that mismatches in these regions of the primers may cause, it is important not to underestimate its potential impact in diagnosis 9 . In addition, mismatches were found for the American and Thai assays for the $\mathrm{N}$ gene and the Chinese assay for ORF1ab, in the 5', 3', and central portions and in the $5^{\prime}$ portion of the probes, respectively, which might induce a decrease or even an absence of fluorescent signal, promoting unfaithful results ${ }^{11}$. Despite the lack of results on Brazilian sequences, Toms et al. ${ }^{12}$ observed the presence of mismatches in the targets of these assays in several other countries.

Our results demonstrated a higher occurrence of four mismatches from the Chinese CN-CDC-N and HKU-N assays in the Brazilian genomes of SARS-CoV-2. The high frequency (Figure 2A and Figure 2B) of G28881A, G28882A, G28883C (151/177), and T29148C (101/177) mutations inside the target regions of both assays might deeply reduce the accuracy of its use in Brazilian samples. In a previous alignment analysis of 17,175 sequences (including 90 Brazilian sequences), the CN-CDC-N assay presented mismatches in more than $18.8 \%$ of the total aligned genomes ${ }^{1}$. In addition, the combination of multiple mismatches, as we found for CN-CDC-N, could directly decrease the amplification performance 9 . A South American study, which included 95 viral sequences deposited by Brazil, also through the GISAID platform, phylogenetically analyzed the genetic diversity of the virus and identified possible mutation hot spots for viral detection within the $\mathrm{N}$ gene ${ }^{13}$. This suggests that the use of tests

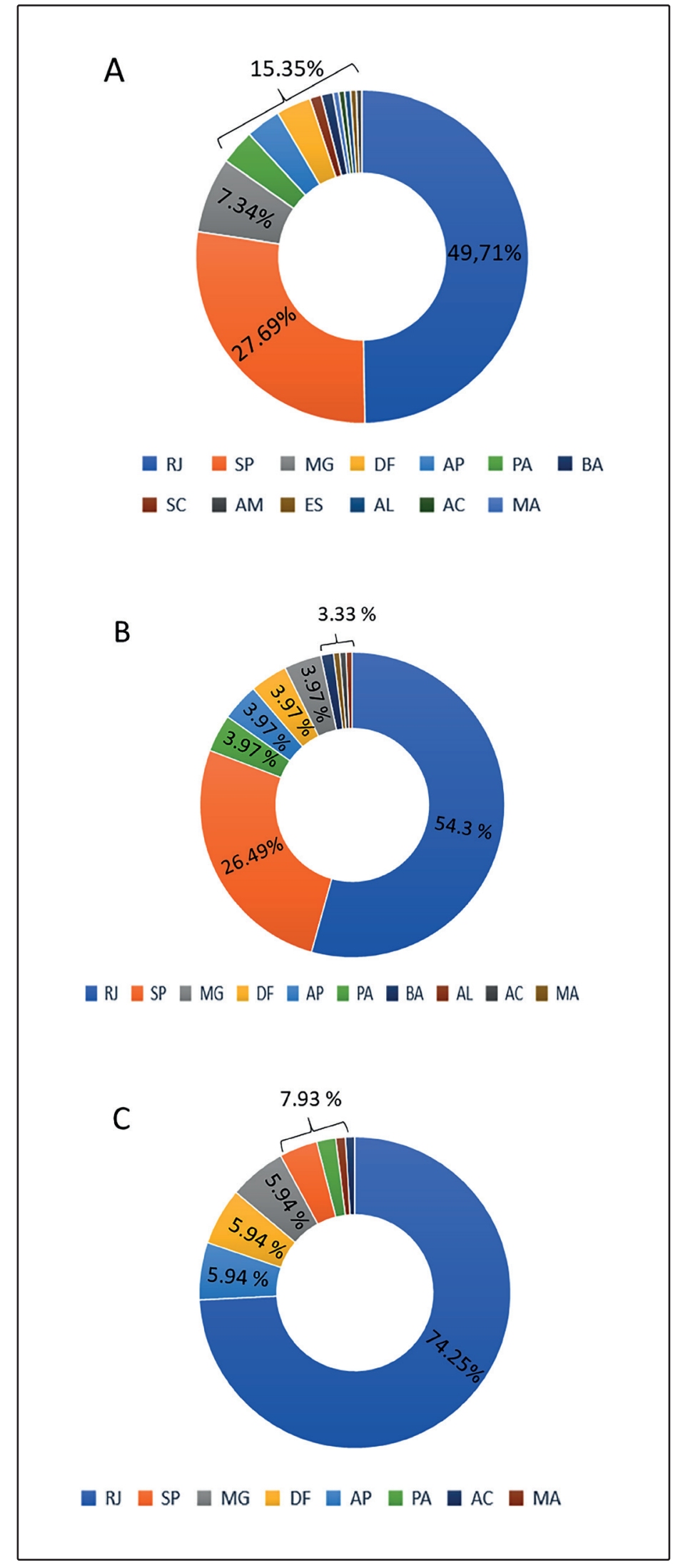

FIGURE 2: (A) Brazilian SARS-Cov-2 genome sequences deposited in the GISAID-EpiCoV platform, divided by state: Rio de Janeiro (RJ), São Paulo (SP), Minas Gerais (MG), Distrito Federal (DF), Amapá (AP), Pará (PA), Bahia (BA), Santa Catarina (SC), Amazona (AM), Espírito Santo (ES), Alagoas (AL), Acre (AC) and Maranhão (MA). Occurrence of the G28881A, G28882A, G28883C (B), and T29148C (C) mutations in each state. 
TABLE 1: List of analyzed assays by targets, frequency and location of mismatches. Each assay below includes three components, 2 primers and 1 probe. Both can be susceptible to matching errors.

\begin{tabular}{|c|c|c|c|}
\hline Assays/Origen & Target & Total frequency of mismatches & Mismatches at $3^{\prime}$ or $5^{\prime}$ portion \\
\hline US-CDC-N1/US-CDC & $\mathrm{N}$ & $3 / 177$ & $5^{\prime}$ and $3^{\prime}$ \\
\hline US-CDC-N2/US-CDC & $\mathrm{N}$ & $2 / 177$ & $5^{\prime}$ \\
\hline US-CDC-N3/US-CDC & $\mathrm{N}$ & $3 / 177$ & $5^{\prime}$ and $3^{\prime}$ \\
\hline NIID_2019-nCOV_N/Japan & $\mathrm{N}$ & $0 / 177$ & - \\
\hline N_Sarbeco/Japan & $\mathrm{N}$ & $1 / 177$ & $3^{\prime}$ \\
\hline CN-CDC-N/China & $\mathrm{N}$ & $151 / 177$ & $5^{\prime}$ \\
\hline HKU-N/Hong Kong & $\mathrm{N}$ & $103 / 177$ & $5^{\prime}$ and $3^{\prime}$ \\
\hline $\mathrm{NIH}-\mathrm{TH} \_\mathrm{N} /$ Thailand & $\mathrm{N}$ & $2 / 177$ & 5 \\
\hline Corman-N/Germany & $\mathrm{N}$ & $1 / 177$ & $3^{\prime}$ \\
\hline nCoV_IP2/France & ORF1ab & $1 / 177$ & 5 \\
\hline nCoV_IP4/France & ORF1ab & $0 / 177$ & - \\
\hline CN-CDC-ORF1ab/China & ORF1ab & $2 / 177$ & $5^{\prime}$ \\
\hline Charité-E/Germany & $E$ & $2 / 177$ & $5^{\prime}$ \\
\hline CN-CDC-E/Germany & $E$ & $0 / 177$ & - \\
\hline E_Sarbeco/France & $E$ & $2 / 177$ & $5^{\prime}$ \\
\hline
\end{tabular}

Note that the Chinese and Hong Kong assays for the $\mathrm{N}$ gene have many mismatches compared to the others. ORF1ab and $\mathrm{E}$ targets are less frequent in 3 'mismatches.

designed by the Chinese CDC and the University of Hong Kong needs to be carefully evaluated, in view of the existence of mutated strains in the targets of these assays in the Brazilian territory. This conclusion was also pointed out by Candido et al. ${ }^{14}$. However, our results include additional data for May, June, and July and take into account only high-coverage sequences. The sequencing quality depends directly on a robust coverage ${ }^{15}$, which is a key factor to be considered, especially in the evaluation of how mismatches could impact diagnosis.

Interestingly, molecular diagnoses by RT-PCR have shown a conflict with the hospital scenario and clinical parameters. Di Paolo et al. ${ }^{16}$ reported what happened in an intensive care unit in Rome. At the admission of 69 patients on May 19, 13 of them (23.2\%) had a high suspicion of presenting the disease based on clinical parameters and chest high-resolution computed tomography (HRCT). However, these patients obtained negative results for diagnostic RT-PCR in three independent analyses. In Beijing, cases of false-negatives by molecular results were identified in two out of ten cases (20\%) at the beginning of the pandemic. Considering this issue, the National Health Commission of China established the concept of "Clinical diagnosis" for cases like these, using RT-PCR data for patient isolation matters ${ }^{17}$.

Out of the 177 selected SARS-CoV-2 genome sequences, $77.4 \%$ (137/177) were from only two states (Figure 2A), SP and RJ, both located in the southeast region of the country. The 40 remaining sequences were divided among the states of Minas Gerais, Amapá, Pará, Bahia, Alagoas, Acre, Maranhão, Santa Catarina, Amazonas, Espírito Santo and Distrito Federal. SP and RJ were indeed very affected by the pandemic. However, other states, such as Ceará, Bahia, and Pará, were also deeply affected ${ }^{3}$. Nevertheless, the number of complete high-coverage sequences deposited for those states are not representative, or in some cases nonexistent. This vast distinction regarding the number of available sequences between SP and RJ and the other states may be due to their higher Human Development Index (HDI) associated with being the two largest economic centers in Brazil ${ }^{18}$.

Other studies have evaluated the specificity of several PCR assays to sequences from different countries or continents ${ }^{1,12}$. They also found that the assays targeting $\mathrm{N}$ exhibited more mismatches than the others, which could be due to the existence of more published assays targeting this region. Additionally, the Chinese PCR assays exhibited a higher mismatch than any other assay when aligned to sequences from several countries. Although the mutation rate of SARS-CoV-2 is apparently lower than that of the first SARS-CoV, which has two mutations per human passage ${ }^{19}$, periodic monitoring of the PCR assay protocols is necessary nonetheless.

From the 15 primers and probes analyzed in this study, our results suggest the PCR assays NIID_2019-nCOV_N, nCoV_IP4, and CNCDC-E are ideal for SARS-CoV-2 diagnosis in Brazil. The selection of assays used in Brazil must be done with caution, considering that the use of primers and probes containing mismatches may lead to false negative results. Certainly, the imprecision of a final result may result from several factors such as incorrect sample handling, transport, storage, insufficient viral material, and contamination ${ }^{20}$, but also from non-functional or poorly validated RT-PCR assays ${ }^{13,16}$. 
Until now, Brazil has not presented studies reporting the rate of false-negative cases of RT-PCR results, but these possible diagnostic failures may lead to incorrect conduct, contribute to breaks in social isolation, and impact on epidemiological surveillance, increasing the risk of infection.

As the number of high-coverage genomes deposited from states other than SP and RJ was low, our results have a regional bias. It is also important to highlight that we did not perform in vitro comparisons between the assays, and our conclusions are based solely on in silico analysis.

\section{ACKNOWLEDGEMENTS}

Authors are thankful to Fundação Edson Queiroz for financial and infrastructure support. We acknowledge authors for their efforts in the work of sequencing samples and submitting them via the GISAID Initiative (Supplementary Data S2).

\section{FINANCIAL SUPPORT}

This work was supported by Edson Queiroz Foundation.

\section{AUTHOR'S CONTRIBUTIONS}

RSS, RSCB, DML and KCST: designed the study; RSS and RSCB researched the data and performed the experiments; RSS, RSCB, DML, ACOMM, ARCB, ARAS and KCST: analyzed data and wrote the manuscript. All authors read and approved the final manuscript.

\section{CONFLICTS OF INTEREST}

The authors declare that there are no conflicts of interests.

\section{REFERENCES}

1. Khan KA, Cheung P. Presence of mismatches between diagnostic PCR assays and coronavirus SARS-CoV-2 genome. R Soc Open Sci 2020;7:200636. https://doi.org/10.1098/rsos.200636.

2. Worldometers. COVID-19 coronavirus pandemic [Internet]. Worldometers; 2020 [updated 2020 April 24; cited 2020 July 27]. Available from: https://www.worldometers.info/coronavirus/ coronavirus-symptoms/

3. Ministério da Saúde (MS). DATASUS. Secretaria de Vigilância em Saúde. Painel Coronavírus [Internet]. Ministério da Saúde (MS); 2020. [cited 2020 July 28]. Available from: https://covid.saude.gov.br/

4. Carter LJ, Garner LV, Smoot JW, Li Y, Zhou Q, Saveson CJ, et al. Assay Techniques and Test Development for COVID-19 Diagnosis. ACS Cent Sci. 2020;6:591-605. https://doi.org/10.1021/acscentsci.0c00501.

5. World Health Organization (WHO). In-house developed molecular assays [Internet]. World Health Organization (WHO); 2020 [cited 2020 July 25]. Available from: who.int/docs/default-source/coronaviruse/ whoinhouseassays.pdf?sfvrsn=de3a76aa_2

6. Pachetti M, Marini B, Benedetti F, Giudici F, Mauro E, Storici P, et al. Emerging SARS-CoV-2 mutation hot spots include a novel RNAdependent-RNA polymerase variant. J Transl Med. 2020;18:179. https:// doi.org/10.1186/s12967-020-02344-6.
7. Elbe S, Buckland-Merrett G. Data, disease and diplomacy: GISAID's innovative contribution to global health. Glob Challenges. 2017;1:3346. https://doi.org/10.1002/gch2.1018.

8. Thompson JD, Higgins DG, Gibson TJ. CLUSTAL W: Improving the sensitivity of progressive multiple sequence alignment through sequence weighting, position-specific gap penalties and weight matrix choice. Nucleic Acids Res. 1994;22:4673-80. https://doi.org/10.1093/nar/22.22.4673.

9. Stadhouders R, Pas SD, Anber J, Voermans J, Mes THM, Schutten M. The effect of primer-template mismatches on the detection and quantification of nucleic acids using the $5^{\prime}$ nuclease assay. J Mol Diagnostics. 2010;12:109-17. https://doi.org/10.2353/jmoldx.2010.090035.

10. Lefever S, Pattyn F, Hellemans J, Vandesompele J. Single-nucleotide polymorphisms and other mismatches reduce performance of quantitative PCR assays. Clin Chem. 2013;59:1470-80. https://doi. org/10.1373/clinchem.2013.203653.

11. Wang Y, Miao ZH, Pommier Y, Kawasaki ES, Player A. Characterization of mismatch and high-signal intensity probes associated with Affymetrix genechips. Bioinformatics. 2007;23:2088-95. https://doi.org/10.1093/ bioinformatics/btm306.

12. Toms D, Li J, Cai HY. Evaluation of WHO listed COVID-19 qPCR primers and probe in silico with 375 SERS-CoV-2 full genome sequences. MedRxiv 2020:2020.04.22.20075697. https://doi.org/10.110 1/2020.04.22.20075697.

13. Ramírez JD, Muñoz M, Hernández C, Flórez C, Gomez S, Rico A, et al. Genetic diversity among sars-cov2 strains in South America may impact performance of molecular detection. Pathogens. 2020;9:1-14. https://doi.org/10.3390/pathogens9070580.

14. Candido DS, Claro IM, de Jesus JG, Souza WM, Moreira FRR, Dellicour $\mathrm{S}$, et al. Evolution and epidemic spread of SARS-CoV-2 in Brazil. Science (80- ) 2020;2161:eabd2161. https://doi.org/10.1126/science.abd2161.

15. Sims D, Sudbery I, Ilott NE, Heger A, Ponting CP. Sequencing depth and coverage: Key considerations in genomic analyses. Nat Rev Genet. 2014;15:121-32. https://doi.org/10.1038/nrg3642.

16. Di Paolo M, Iacovelli A, Olmati F, Menichini I, Oliva A, Carnevalini M, et al. False-negative RT-PCR in SARS-CoV-2 disease: experience from an Italian COVID-19 unit. ERJ Open Res. 2020;6:00324-2020. https:// doi.org/10.1183/23120541.00324-2020.

17. Li D, Wang D, Dong J, Wang N, Huang H, Xu H, et al. False-negative results of real-time reverse-transcriptase polymerase chain reaction for severe acute respiratory syndrome coronavirus 2: Role of deeplearning-based ct diagnosis and insights from two cases. Korean $\mathrm{J}$ Radiol. 2020;21:505-8. https://doi.org/10.3348/kjr.2020.0146.

18. Instituto Brasileiro de Geografia e Estatistica (IBGE). Índice de Desenvolvimento Humano [Internet]. Brasil: Instituto Brasileiro de Geografia e Estatistica (IBGE); 2010 [cited 2020 July 20]. Available from: https://cidades.ibge.gov.br/brasil/sp/pesquisa/37/0?tipo=ranking.

19. Vega VB, Ruan Y, Liu J, Lee WH, Wei CL, Se-Thoe SY, et al. Mutational dynamics of the SARS coronavirus in cell culture and human populations isolated in 2003. BMC Infect Dis. 2004;4:1-9. https://doi. org/10.1186/1471-2334-4-32.

20. Lippi G, Simundic AM, Plebani M. Potential preanalytical and analytical vulnerabilities in the laboratory diagnosis of coronavirus disease 2019 (COVID-19). Clin Chem Lab Med. 2020;58:1070-6. https://doi. org/10.1515/cclm-2020-0285.

21. Hall, T.A. (1999) BioEdit: A User-Friendly Biological Sequence Alignment Editor and Analysis Program for Windows 95/98/NT. Nucleic Acids Symposium Series, 41, 95-98. 
SUPPLEMENTARY DATA S1: Sequences used for alignment, downloaded from the GISAID-EpiCoV platform.

Identification of 177 deposited sequences using Virus name and Accession ID provided by the GISAID-EpiCoV platform.

Virus name

hCoV-19/Brazil/SP-01/2020

hCoV-19/Brazil/SP-02/2020

hCoV-19/Brazil/SP-03/2020

hCoV-19/Brazil/SP-06/2020

hCoV-19/Brazil/SP-05/2020

hCoV-19/Brazil/SP-04/2020

hCoV-19/Brazil/RJ-314/2020

hCoV-19/Brazil/BA-312/2020

hCoV-19/Brazil/ES-225/2020

hCoV-19/Brazil/SP-07/2020

hCoV-19/Brazil/SP-08/2020

hCoV-19/Brazil/SP-09/2020

hCoV-19/Brazil/SP-10/2020

hCoV-19/Brazil/SP-11/2020

hCoV-19/Brazil/SP-12/2020

hCoV-19/Brazil/SP-13/2020

hCoV-19/Brazil/SP-14/2020

hCoV-19/Brazil/AMBR-02/2020

hCoV-19/Brazil/DFBR-0001/202

hCoV-19/Brazil/AL-837/2020

hCoV-19/Brazil/BA-510/2020

hCoV-19/Brazil/DF-615i/2020

hCoV-19/Brazil/DF-619i/2020

hCoV-19/Brazil/DF-861/2020

hCoV-19/Brazil/DF-862/2020

hCoV-19/Brazil/DF-891/2020

hCoV-19/Brazil/RJ-352/2020

hCoV-19/Brazil/RJ-477/2020

hCoV-19/Brazil/RJ-477i/2020

hCoV-19/Brazil/RJ-763/2020

hCoV-19/Brazil/RJ-818/2020

hCoV-19/Brazil/RJ-872/2020

hCoV-19/Brazil/SC-766/2020

hCoV-19/Brazil/SC-769/2020

hCoV-19/Brazil/CV4/2020

hCoV-19/Brazil/CV6/2020

hCoV-19/Brazil/CV8/2020

hCoV-19/Brazil/CV12/2020

hCoV-19/Brazil/CV16/2020

hCoV-19/Brazil/CV19/2020

hCoV-19/Brazil/CV21/2020

hCoV-19/Brazil/CV26/2020

hCoV-19/Brazil/CV31/2020

hCoV-19/Brazil/CV32/2020

hCoV-19/Brazil/CV33/2020

hCoV-19/Brazil/CV42/2020

hCoV-19/Brazil/CV49/2020

hCoV-19/Brazil/SP02cc/2020
Accession ID

EPI ISL 412964

EPI ${ }^{-}{ }^{-}{ }^{-}{ }^{-} 413016$

EPI ISL ${ }^{-} 414014$

EPI ${ }^{-}{ }^{-}{ }^{-} 414015$

EPI ${ }^{-}{ }^{-}{ }^{-} 414016$

EPI ${ }^{-} \mathrm{ISL}^{-} 414017$

EPI ISL 414045

EPI ISL ${ }^{-} 415105$

EPI ${ }^{-} \mathrm{ISL}^{-}{ }^{-} 15128$

EPI ISI- 416028

EPI'ISL-416029

EPI_ISL_416031

EPI ISI ${ }^{-} 416032$

EPI ${ }^{-} \mathrm{ISL}^{-} 416033$

EPI ${ }^{-} \mathrm{ISL}^{-} 416034$

EPI ISI ${ }^{-} 416035$

EPI ISL 416036

$\mathrm{EPI}^{-}{ }^{-} \mathrm{ISL}^{-} 417034$

0 EPI ISL 426580

EPI ISL $\overline{42} 7292$

EPI_ISL_427293

EPI ISI-427294

EPI'ISL_427295

EPI ${ }^{-}{ }^{-}{ }^{-}{ }^{-} 427296$

EPI ${ }^{-}{ }^{-} \mathrm{SL}^{-} 427297$

EPI ISL ${ }^{-} 427298$

EPI ${ }^{-} \mathrm{ISL}^{-} 427299$

EPI ${ }^{-} \mathrm{ISL}^{-} 427300$

EPI ISL ${ }^{-} 427301$

EPI ${ }^{-} \mathrm{ISL}^{-} 427302$

EPI ${ }^{-} \mathrm{ISL}^{-} 427303$

EPI ISL ${ }^{-} 427304$

EPI_ISL_427305

EPI ISL ${ }^{-} 427306$

EPI ${ }^{-} \mathrm{ISL}^{-} 429667$

EPI_ISL_429669

$\mathrm{EPI}^{-}{ }^{-} \mathrm{ISL}^{-} 429671$

EPI ${ }^{-}{ }^{-}{ }^{-} 429674$

EPI ${ }^{-} \mathrm{ISL}^{-} 429676$

$\mathrm{EPI}^{-} \mathrm{ISL}^{-} 429679$

EPI ISI ${ }^{-} 429681$

EPI ${ }^{-}{ }^{-}{ }^{-} 429684$

EPI ISL 429687

EPI ISI ${ }^{-} 429688$

EPI ISL ${ }^{-} 429689$

EPI ISL ${ }^{-} 429695$

EPI ISI ${ }^{-} 429702$

EPI ISL ${ }^{-} 450506$

hCoV-19/Brazil/AP161167-IEC/2020 EPI ISL 450873

hCoV-19/Brazil/PA161548-IEC/2020 EPI_ISL_450874 
hCoV-19/Brazil/RJ-899/2020 hCoV-19/Brazil/RJ-1056/2020 hCoV-19/Brazil/RJ-1058/2020 hCoV-19/Brazil/RJ-1065/2020 hCoV-19/Brazil/RJ-1100/2020 hCoV-19/Brazil/RJ-1111/2020 hCoV-19/Brazil/RJ-1119/2020 hCoV-19/Brazil/RJ-1402/2020 hCoV-19/Brazil/RJ-1464/2020 hCoV-19/Brazil/RJ-1466/2020 hCoV-19/Brazil/RJ-1600/2020 hCoV-19/Brazil/RJ-1627/2020 hCoV-19/Brazil/RJ-1690/2020 hCoV-19/Brazil/RJ-1691/2020 hCoV-19/Brazil/RJ-1701/2020 hCoV-19/Brazil/RJ-1702/2020 hCoV-19/Brazil/RJ-1719/2020 hCoV-19/Brazil/RJ-1901/2020 hCoV-19/Brazil/RJ-1902/2020 hCoV-19/Brazil/RJ-1921/2020 hCoV-19/Brazil/RJ-1923/2020 hCoV-19/Brazil/RJ-1927/2020 hCoV-19/Brazil/RJ-1943/2020 hCoV-19/Brazil/RJ-1948/2020 hCoV-19/Brazil/RJ-1952/2020 hCoV-19/Brazil/RJ-1966/2020 hCoV-19/Brazil/RJ-2000/2020 hCoV-19/Brazil/RJ-2007/2020 hCoV-19/Brazil/RJ-2033/2020 hCoV-19/Brazil/RJ-2044/2020 hCoV-19/Brazil/RJ-2057/2020 hCoV-19/Brazil/RJ-2062/2020 hCoV-19/Brazil/RJ-2072/2020 hCoV-19/Brazil/RJ-2077/2020 hCoV-19/Brazil/RJ-2078/2020 hCoV-19/Brazil/AP162741-IEC/2020 hCoV-19/Brazil/AC162535-IEC/2020 hCoV-19/Brazil/PA162802-IEC/2020 hCoV-19/Brazil/PA1 64239-IEC/2020 hCoV-19/Brazil/AP162966-IEC/2020 hCoV-19/Brazil/AP164082-IEC/2020 hCoV-19/Brazil/AP163972-IEC/2020 hCoV-19/Brazil/AP1 64346-IEC/2020 hCoV-19/Brazil/PA1 64173-IEC/2020 hCoV-19/Brazil/PA1 64218-IEC/2020 hCoV-19/Brazil/PA1 64684-IEC/2020 hCoV-19/Brazil/MA163069-IEC/2020 hCoV-19/Brazil/RJ-1555/2020 hCoV-19/Brazil/RJ-1574/2020 hCoV-19/Brazil/RJ-1595/2020 hCoV-19/Brazil/RJ-2091/2020 hCoV-19/Brazil/RJ-2195/2020 hCoV-19/Brazil/RJ-2197/2020 hCoV-19/Brazil/RJ-2208/2020
EPI_ISL_456071

EPI ${ }^{-}{ }^{-}{ }^{-} 456072$

EPI_ISL_456073

EPI_ISI_456074

EPI ${ }^{-}{ }^{-}{ }^{-}{ }^{-} 456075$

EPI_ISI-456076

EPI ${ }^{-} \mathrm{ISL}^{-} 456077$

EPI ${ }^{-} \mathrm{ISL}^{-} 456079$

EPI ${ }^{-} \mathrm{ISL}^{-} 456080$

EPI ${ }^{-} \mathrm{ISL}^{-}{ }^{-456081}$

EPI ${ }^{-} \mathrm{ISL}^{-} 456082$

EPI ISL ${ }^{-} 456083$

EPI ISI ${ }^{-} 456084$

EPI ${ }^{-}{ }^{-}{ }^{-}{ }^{-} 456085$

$\mathrm{EPI}^{-}{ }^{-} \mathrm{ISL}^{-} 456086$

EPI_ISL_456087

EPI-ISI-456088

EPI ${ }^{-} \mathrm{ISL}^{-} 456089$

$\mathrm{EPI}^{-}{ }^{-} \mathrm{ISL}^{-} 456090$

EPI ${ }^{-} \mathrm{ISL}^{-} 456091$

EPI ${ }^{-} \mathrm{ISL}^{-} 456092$

EPI_ISL_456093

EPI ISL 456094

EPI ISL ${ }^{-} 456095$

EPI ISL ${ }^{-} 456096$

EPI ${ }^{-}{ }^{-}{ }^{-}{ }^{-} 456097$

$\mathrm{EPI}^{-}{ }^{-} \mathrm{ISL}^{-} 456098$

EPI ${ }^{-}{ }^{-}{ }^{-}{ }^{-} 456099$

EPI-ISL_456100

EPI ISL-456101

$\mathrm{EPI}^{-}{ }^{-} \mathrm{ISL}^{-} 456102$

EPI ${ }^{-} \mathrm{ISL}^{-} 456103$

EPI ISL 456104

EPI ISL 456105

$\mathrm{EPI}^{-} \mathrm{ISL}^{-} 456106$

EPI ISL 458138

EPI_ISL_458139

EPI ${ }^{-} \mathrm{ISL}^{-}{ }^{-} 458140$

EPI ISL ${ }^{-} 458141$

$\mathrm{EPI}^{-}{ }^{-\mathrm{ISL}^{-}}{ }^{-} 458142$

$\mathrm{EPI}^{-} \mathrm{ISL}^{-} 458143$

EPI ${ }^{-} \mathrm{ISI}^{-}{ }^{-} 458144$

EPI ${ }^{-} \mathrm{ISL}^{-} 458145$

EPI ${ }^{-} \mathrm{ISL}^{-} 458146$

EPI ${ }^{-} \mathrm{ISL}^{-}{ }^{-} 458147$

EPI ${ }^{-} \mathrm{ISL}^{-} 458148$

EPI ${ }^{-} \mathrm{ISL}^{-} 458149$

EPI ISL $4 \overline{6} 734 \overline{4}$

EPI ISL ${ }^{-} 467345$

EPI ISI ${ }^{-} 467346$

EPI ${ }^{-} \mathrm{ISL}^{-} 467347$

EPI_ISL_467348

EPI_ISI-467349

EPI_ISI_467350 
hCoV-19/Brazil/RJ-2233/2020 hCoV-19/Brazil/RJ-2422/2020 hCoV-19/Brazil/RJ-2669/2020 hCoV-19/Brazil/RJ-2676/2020 hCoV-19/Brazil/RJ-2678/2020 hCoV-19/Brazil/RJ-2682/2020 hCoV-19/Brazil/RJ-2683/2020 hCoV-19/Brazil/RJ-2696/2020 hCoV-19/Brazil/RJ-2717/2020 hCoV-19/Brazil/RJ-2733/2020 hCoV-19/Brazil/RJ-2769/2020 hCoV-19/Brazil/RJ-2770/2020 hCoV-19/Brazil/RJ-2776/2020 hCoV-19/Brazil/RJ-2777/2020 hCoV-19/Brazil/RJ-2811/2020 hCoV-19/Brazil/RJ-2812/2020 hCoV-19/Brazil/RJ-2822/2020 hCoV-19/Brazil/RJ-2840/2020 hCoV-19/Brazil/RJ-2844/2020 hCoV-19/Brazil/RJ-2847/2020 hCoV-19/Brazil/RJ-2868/2020 hCoV-19/Brazil/SP-138/2020 hCoV-19/Brazil/SP-139/2020 hCoV-19/Brazil/SP-140/2020 hCoV-19/Brazil/SP-141/2020 hCoV-19/Brazil/SP-144/2020 hCoV-19/Brazil/SP-146/2020 hCoV-19/Brazil/SP-147/2020 hCoV-19/Brazil/SP-148/2020 hCoV-19/Brazil/SP-149/2020 hCoV-19/Brazil/sP-500/2020 hCoV-19/Brazil/SP-504/2020 hCoV-19/Brazil/SP-505/2020 hCoV-19/Brazil/SP-506/2020 hCoV-19/Brazil/SP-508/2020 hCoV-19/Brazil/SP-516/2020 hCoV-19/Brazil/SP-47/2020 hCoV-19/Brazil/SP-126/2020 hCoV-19/Brazil/SP-127/2020 hCoV-19/Brazil/SP-131/2020 hCoV-19/Brazil/SP-601/2020 hCoV-19/Brazil/SP-537/2020 hCoV-19/Brazil/SP-606/2020 hCoV-19/Brazil/SP-607/2020 hCoV-19/Brazil/SP-545/2020 hCoV-19/Brazil/SP-549/2020 hCoV-19/Brazil/SP-551/2020 hCoV-19/Brazil/SP-512/2020 hCoV-19/Brazil/SP-523/2020 hCoV-19/Brazil/SP-524/2020 hCoV-19/Brazil/SP-525/2020 hCoV-19/Brazil/SP-526/2020 hCoV-19/Brazil/SP-527/2020 hCoV-19/Brazil/RJ01/2020
EPI ISL 467351 EPI ISL 467352 $\mathrm{EPI}^{-} \mathrm{ISL}^{-} 467353$ EPI ${ }^{-} \mathrm{ISL}^{-} 467354$ EPI ISL 467355 EPI ${ }^{-} \mathrm{ISL}^{-} 467356$ EPI ISL 467357 EPI ${ }^{-} \mathrm{ISL}^{-} 467358$ $\mathrm{EPI}^{-} \mathrm{ISL}^{-} 467359$ EPI_ISL_467360 EPI ISL 467361 $\mathrm{EPI}^{-}{ }^{-\mathrm{ISL}^{-}} 467362$ $\mathrm{EPI}^{-} \mathrm{ISL}^{-} 467363$ EPI ISL 467364 $\mathrm{EPI}^{-}{ }^{-\mathrm{ISL}^{-}}{ }^{-} 67365$ EPI ${ }^{-} \mathrm{ISL}^{-} 467366$ EPI ${ }^{-} \mathrm{ISL}^{-} 467367$ $\mathrm{EPI}^{-} \mathrm{ISL}^{-} 467368$ EPI ISL ${ }^{-} 467369$ EPI ISL_467370 EPI ${ }^{-}$ISL $^{-} 467371$ $\mathrm{EPI}^{-}{ }^{-} \mathrm{ISL}^{-} 468305$ EPI ${ }^{-} \mathrm{ISL}^{-} 468306$ EPI ${ }^{-}$ISL $^{-} 468307$ EPI ${ }^{-} \mathrm{ISL}^{-} 468308$ EPI ISL 468310 EPI ${ }^{-} \mathrm{ISL}^{-} 468311$ EPI ${ }^{-} \mathrm{ISL}^{-} 468312$ EPI ${ }^{-}{ }^{-}{ }^{-} 468313$ EPI_ISL_468314 EPI ISL 468315 EPI ${ }^{-} \mathrm{ISL}^{-} 468316$ EPI ISL_468318 EPI ${ }^{-}$ISL $^{-} 468319$ EPI ${ }^{-} \mathrm{ISL}^{-}{ }^{-} 468320$ EPI ISL ${ }^{-} 468321$ EPI ${ }^{-} \mathrm{ISL}^{-} 471539$ EPI ${ }^{-}$ISL $^{-} 471541$ EPI ${ }^{-} \mathrm{ISL}^{-} 471542$ EPI ${ }^{-}$ISL $^{-} 471543$ EPI ISL 471545 EPI ISL 471546 EPI ${ }^{-}$ISL $^{-} 471548$ EPI ${ }^{-} \mathrm{ISL}^{-} 471549$ EPI_ISL 471551 $\mathrm{EPI}^{-} \mathrm{ISL}^{-} 471552$ EPI ISL 471554 EPI ${ }^{-}{ }^{-}{ }^{-}{ }^{-} 471556$ EPI ${ }^{-}$ISL $^{-} 471562$ EPI ${ }^{-}$ISL $^{-} 471581$ EPI ISL 471582 EPI ISL 471647 EPI_ISL_471648 EPI_ISL_483065 


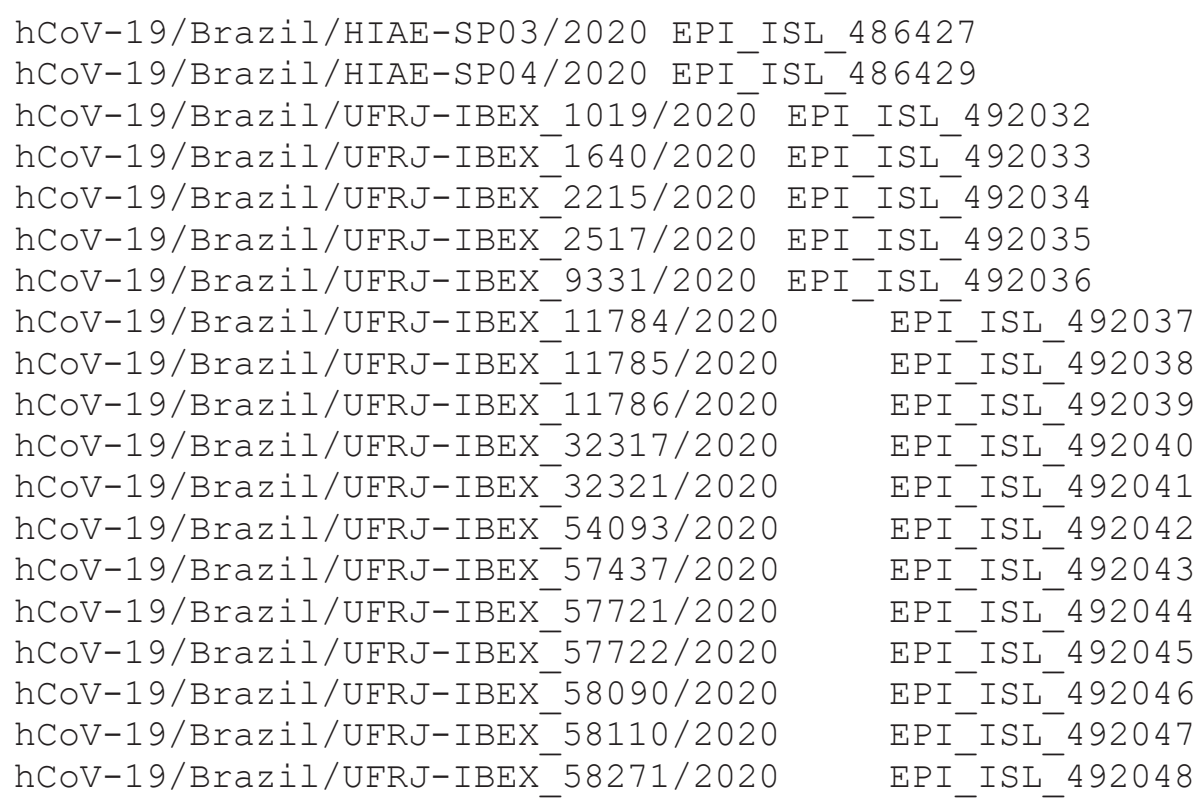


SUPPLEMENTARY DATA S2: List of laboratories involved in the deposition of viral sequences.

Illy acknowledge the following Authors from the Originating laboratories responsible for obtaining the specimens, as well as the laboratories where the genome data were generated and shared via GISAID, on which this research is based.

ers of data may be contacted directly via www.gisaid.org

Accession ID
EP_ISL_412964

EPLISL_-413016

EP_ISL_414014
EPLISL_414015

EPL_ISL_414016

EPL_ISL_414017

EPL_ISL_414045

EPI_ISL_415105

EPLISL_-415128

EPPLISL 416028

EPLISL_416029

ISL_416031, EPL_ISL_416032

ISL_416033, EPP_ISL_416034

ISL_416035, EPL_ISL_416036

EPP_ISL_417034

EPIISL_426580

EPPILLL_427292

EPI_SL_427293

4, EPL_ISL_427295,

see above

ISL_427305, EPL_ISL_427306

7.EPI_ISL_429669, EP_IIL_429671, EP_ISL_429674, EPL_ISL_429676, EP_ISL_429681, EPI_ISL_429687,

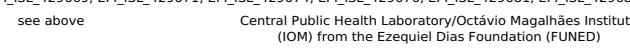

EPI_ISL_450873

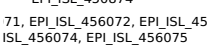

ISL_456076, EPP_ISL_456077

179, EPPIISL_456080, EPI_ISL_45608

ISL_456082, EPL_ISL_456083

84, EPIISL_456085, EPLISL_456086,

EPIISL 456088

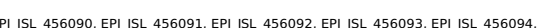

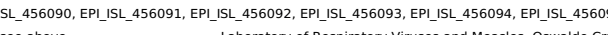

Laboratory of Respiratory Viruses and Measles, Oswaldo Cruz
Institute, Evandro chagas institute

Laboratory of Respiratory Viruses and Measles, Oswaldo Cruz
Institute, FIICRUZ

LACEN R] - Laboratório Central de Saúde Pública Noel Nutes

Laboratory of Respiratory Viruses and Measles, Oswaldo Cruz
Institute, flocRuZ

LACEN RJ - Laboratório Central de Saúde Pública Noel Nutes

Laboratory of Respiratory Viruses and Measles, Oswaldo Cinz

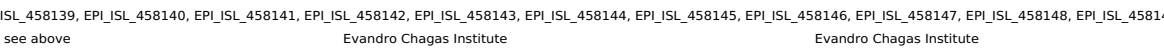

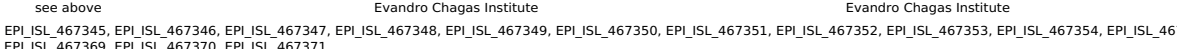
see above Laboratory of Respiratory Viruses and Measles, Oswaldo Cruz Laboratory of Respiratory Viruses and Measles, Oswaldo Cruz Institute,
Institute, FIOCRUZ

ISL_468305, EP__SL_468307

EPI_ISL_468308

(SL_-468311, EP_ISL_468312

EPIIISL_468313
EPIISL_468314

EPIIILL4668314

EPI_ISL_468315

EPL_ISL_46831

\section{Submitting Laboratory}

(1) Instituto Adolfo Lutz, Interdicipilinary Procedures Center, Strategic Laboratory Instituto Adolfo Lutz, Interdicipininary Procedures Center, Strategic Laboratory

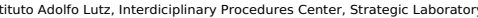
Instituto Adolfo Instituto Oswaldo Cruz FlOCRUZ - Laboratory of Respiratory Viruses and
Measles (LVRS) Instituto Oswaldo Cruz FIOCRUZ- Laboratory of Respiratory Viruses and
Measles (LVRS) Instituto Oswaldo Cruz FIOCRUZ - Laboratory of Respiratory Viruses and Instituto Adolfo Lutz, Interdiciplinary Procedures Center, Strategic Laborad Instituto Adolfo Lutz, Interdiciplinary Procedures Center, Strategic Laboratory

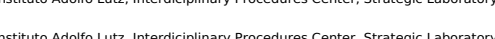
Instituto Adolfo Lutz, Interdicipilinary Procedures Center, Strategic Laboratory Laboratorio de Eceologia de Doencas Transmissiveis na Amazonia, Institututo
Leoniidas e Maria Deane - Fiocruz Amazonia Laboratory of Virology Measles (LVRS)
Instituto Oswaldo Cruz FIOcRUZ - Laboratory of Respiratory Viruses and
Measles (LLRS)

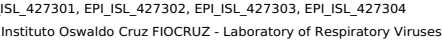
Instituto Oswaldo Cruz FIOCRUZ - Laboratory of Respiratory Viruses and

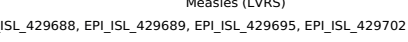

$\begin{aligned} & \text { Evandro Chagas Institute } \\ & \text { Evandro chagas Institute }\end{aligned}$
Laboratory of Respiratory Viruses and Measles, Oswaldo Cruz Institute.
FiOCRUZ

Laboratory of Respiratory Viruses and Measles, Oswaldo Cruz Institute.
FIOCRUZ Laboratory of Respiratory Viruses and Measles, Oswaldo Cruz Institute.
FICCRUZ Laboratory of Respiratory Viruses and Measles, Oswaldo Cruz Institute.
FlOCRUZ Laboratory of Respiratory Viruses and Measles, Oswaldo Cruz Institute,
FICCRUZ Laboratory of Respiratory Viruses and Measles, Oswaldo Cruz Institute,
FIOCRUZ ISL_456096, EPL_ISL_456097, EP_IISL_456098, EP_ISL_456099, EPLISL_4
Laboratory of Respiratory Viruses and Measles, Oswaldo Cruz Institute. Instituto Adolfo Lutz, Interdicipilinary Procedures Center, Strategic Laboratory Instituto Adoffo Lutz, Interdicipininary Procedures Center, Strategic Laboratorn Instituto Adolfo Lutz, Interdicipininary Procedures Center, Strategic Laboratory Instituto Adolfo Lutz, Interdicipininary Procecedures Senter, Strategic Laboratory

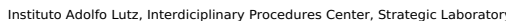
Instituto Adolfo Lutz, Interdicipininary Procedures Center, Strategic Laboratory
Instituto OSwaldo Cruz FlockUZ - Laboratory of Respiratory Viruses and
Measles (IVRS) Instituto Adorfo Lutz, Interdicicipinary Procedures Center, strategic Laboratory
Authors

Jeline Goes de Jesus, Claudio Tavares Sacchi, Daniela Bernardes Borges da Silva, Ingra Morales Claro, Flavia Cristina da Silva Sales, Claudia Regina Goncalves, Joshua Quick, Maria do Car
Tavares Timenetsky, Nicholas James Loman, Andrew Rambautt, Ester Cerdeira sabino, Nuno Rodrigues Faria Fabiana Cristina Pereira dos Santos. Ingra Morales Claro, Fláviva Cristina da Silva Sales, Claudia Regina Goncalves, Joshua Quick, Maria do Ca

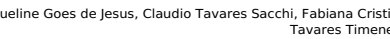

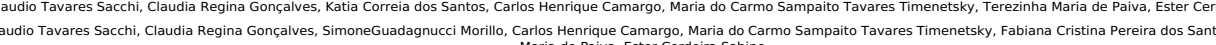
Claudio Tavares Sacchi, Claudia Regina Gonçalves, Audrey Cilil, Carlos Henrique Camargo, Maria do Carmo Sampaitt Tavares Timenetsky, Daniela Bernardes Borges da Silva, Terezinha Mar Claudio Tavares Sacchi, Claudia Regina Gongalves, Fabiana Cristina Pereira dos Santos, , carlos senrique Camargo, Maria do Carmo Sampaito Tavares Timenetsky, Daniela Bernardes Borge Paola Resende, Alisson Fabri, Joilson Xavier, Sunando Roy, Fernando Motta, Aline Mattos, Miliene Miranda, ristiana Garcia, Braulia Caetano, Maria Ogrzewalska, Jonathan Lopes, Luciana Appo Paola Resende, Allison Fabri, Joilson Xavier, Sunando Roy, Fernando Motta, Aline Mattos, Miliene Miranda, Cristiana Garcia, Braulia Caetano, Maria Ogrzewalska, Jonathan Lopes, Luciana Appo aola Resende, Allison Fabri, Joilson Xavier, Sunando Roy, Fernando Motta, Aline Mattos, Milene Miranda, Cristiana Garcia, Braulia Caetano, Marria Ogrrewalska, Jonathan Lopes, Luciana Appo

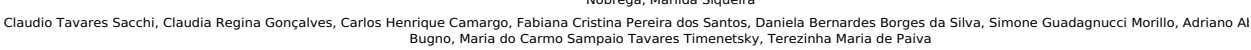
Claudio Tavares Sacchi, Claudia Regina Gonçalves, Carlos Henrique Camargo, Fabiana Cristina Pereira dos Santos, Daniela Bernardes Borges da Silva, Simone Guadagnucci Morillo, Adriano At
Bugno, Maria do Carmo Sampaio Tavares Timenetsky, Terzzinha Maria de Paiva udio Tavares Sacchi, Claudia Regina Gonçalves, Carlos Henrique Camargo, Fabiana Cristina Pereira dos Santos, Daniela Bernardes Borges da silva, Simone Guadagnucci Morillo, Adriano Al
Bugno, Maria do Carmo Sampaio Tavares Timenetsky, Terezinha Maria de Paiva

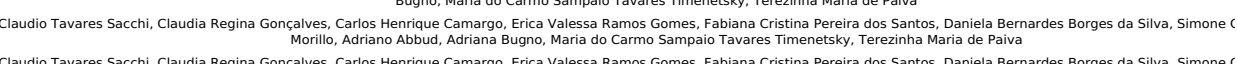
Claudio Tavares Sacchi, Claudia Regina Gongalves, Carlos Henrique Camargo, Erica Valessa Ramos Gomes, Fabiana Cristina Pereira dos Santos, Daniela Berf
Morillo, Adriano Abbud, Adriana Bugno, Maria do Carmo Sampaio Tavares Timenetsky, Terezinha Maria de Paiva

Valdinete Nascimento, André Corado, Fernanda Nascimento, Ágatha costa, Debora Duarte, Luciana Gonçalves, Michele Jesus, Sérgio Luz, Felipe Naveca

Fernando L Melo, Gustavo Barra, Ticiane H Santa-Rita, Pedro G Mesquita, Ikaro A Andrade, Tatsuya Nagata, Bergmann M Ribeiro

Paola Resende, Fernando Motta, Luciana Appolinario, Sunando Roy, Aline Mattos, Milene Miranda, Cristiana Garcia, Braulia Caetano, Maria Ogrzewalska, Priscila Born, Jonathan Lopes, Maril

Paola Resende, Fernando Motta, Luciana Appolinario, Sunando Roy, Aline Mattos, Milene Miranda, Cristiana Garcia, Braulia Caetano, Maria Ogrzewalska, Priscila Born, Jonathan Lopes, Maril.

Paola Resende, Fernando Motta, Luciana Appolinario, Sunando Roy, Aline Mattos, Milene Miranda, Cristiana Garcia, Braulia Caetano, Maria Ogrzewalska, Priscila Born, Jonathan Lopes, Maril Paola Resende, Fernando Motta, Luciana Appolinario, Sunando Roy, Aline Mattos, Milene Miranda, Cristiana Garcia, Braulia Caetano, Maria ogrzewalska, Priscila Born, Jonathan Lopes, Maril

Talita Adelino, Joilson Xavier, Marta Givvanetti, Vagner Fonseca, Marcos Vinicius Silva, Luiz Carlos Junior Alcantara, Marluce Aparecida Assunņăo Oliverira

Santos, M.C.; Silva, A.M.; Junior, W.D.D.C;: Barbagelata, L.S.; Ferreira, J.A.; Sousa, E.M.A; da Silva, P.S.; Martins, L.C.; Sousa Junior, E.C.; Viana, G.M. Paola Resende, Luciana Appolinario, Fernando Motta, Aline Mattos, Milene Miranda, Cristiana Garcia, Braulia caetano, Maria ogrzewalska, Jonathan Lopes, Marilda Siqueira Paola Resende, Luciana Appolinario, Fernando Motta, Aline Mattos, Milene Miranda, Cristiana Garcia, Braulia Caetano, Maria Ogrzewalska, Jonathan Lopes, Marilida Siqueira Paola Resende, Luciana Appolinario, Fernando Motta, Aline Mattos, Milene Miranda, Cristiana Garcia, Braulia Caetano, Maria Ogrzewalska, Jonathan Lopes, Marilda Siqueirz Paola Resende, Luciana Appolinario, Fernando Motta, Aline Mattos, Milene Miranda, Cristiana Garcia, Braulia Caetano, Maria Ogrzewalska, Jonathan Lopes, Marilida Siqueira Paola Resende, Luciana Appolinario, Fernando Motta, Aline Mattos, Milene Miranda, Cristiana Garcia, Braulia Caetano, Maria Ogrzewalska, Jonathan Lopes, Marilda Siqueira Paola Resende, Luciana Appolinario, Fernando Motta, Aline Mattos, Milene Miranda, Cristiana Garcia, Braulia Caetano, Maria Ogrrewalska, Jonathan Lopes, Marilda siqueira 101, EPL_IL__456102, EPL_ISL_456103, EPL_IS__456104, EPL_ISL_456105, EPP_ISL_456106

Santos, M.C.; Silva, A.M.; Junior, W.D.C.; Barbagelata, L.S.; Ferreira, J.A.; Sousa, E.M.A; da Silva, P.S.; Resque, H.R; Martins, L.C.; Sousa Junior, E.C.; Viana, G.M.R

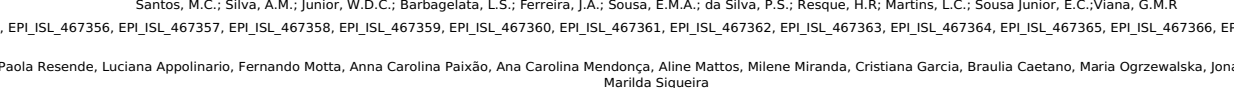
Marilda Siqueira
Claudio Tavares Sacchi, Claudia Regina Goncalves, Erica Valessa Ramos Gomes Claudio Tavares Sacchi, Claudia Regina Gongalves, Erica Valessa Ramos Gomes Claudio Tavares Sacchi, Claudia Regina Gonçalves, Erica Valessa Ramos Gomes Claudio Tavares Sacchi, Claudia Regina Gongalves, Erica Valessa Ramos Gomes Claudio Tavares Sacchi, Claudia Regina Gonnalves, Eric Valessa Ramos Gomes
Claudio Tavares Sacchi, claudia Regina Gonşalves, Erica Valessa Ramos Gomes Claudio Tavares Sacchi, Claudia Regina Gonçalves, Erica Valessa Ramos Gomes Claudio Tavares Sacchi, Claudia Regina Gonçalves, Erica Valessa Ramos Gomes 


\begin{tabular}{|c|c|c|c|}
\hline EPI_ISL_468321 & Hospital Universitario da USP & Instituto Adolfo Lutz, Interdiciplinary Procedures Center, Strategic Laboratory & Claudio Tavares Sacchi, Claudia Regina Gonçalves, Erica Valessa Ramos Gomes \\
\hline EPI_ISL_471539 & Hospital Universitario da USP Sao Paulo & Instituto Adolfo Lutz, Interdiciplinary Procedures Center, Strategic Laboratory & Claudio Tavares Sacchi, Claudia Regina Gonçalves, Erica Valessa Ramos Gomes \\
\hline EPI_ISL_-471541 & Hospital Geral Santa Marcelina & Instituto Adolfo Lutz, Interdicipilinary Procedures Center, Strategic Laboratory & Claudio Tavares Sacchi, Claudia Regina Gonģalves, Erica Valessa Ramos Gomes \\
\hline EPI_ISL_471542 & Secretaria de Saude de Mogi das Cruzes & Instituto Adolfo Lutz, Interdicipininary Procedures Center, Strategic Laboratory & Claudio Tavares Sacchi, Claudia Regina Gonçalves, Erica Valessa Ramos Gomes \\
\hline EPI_ISL_-471543 & Centro de Saude I Tacito Leite de Carvalho e Silva & Instituto Adolfo Lutz, Interdicipininary Procedures Center, Strategic Laboratory & Claudio Tavares Sacchi, Claudia Regina Gonçalves, Erica Valessa Ramos Gomes \\
\hline EPI_ISL_471545 & Hospital Sao Paulo de Ensino da Unifesp & Instituto Adolfo Lutz, Interdicipininary Procedures Center, Strategic Laboratory & Claudio Tavares Sacchi, Claudia Regina Gonçalves, Erica Valessa Ramos Gomes \\
\hline EPI_ISL_471546 & AMA DR Jose Soares Hungria & Instituto Adolfo Lutz, Interdiciplinary Procedures Center, Strategic Laboratory & Claudio Tavares Sacchi, Claudia Regina Gonçalves, Erica Valessa Ramos Gomes \\
\hline EPI_ISL_471548 & $\begin{array}{l}\text { Hospital do Servidor Público Estadual Francisco Morato de } \\
\text { Oliveira }\end{array}$ & Instituto Adolfo Lutz, Interdiciplinary Procedures Center, Strategic Laboratory & Claudio Tavares Sacchi, Claudia Regina Gonģalves, Erica Valessa Ramos Gomes \\
\hline EPI_ISL_471549 & Hospital Municipal Carmen Prudente & Instituto Adolfo Lutz, Interdiciplinary Procedures Center, Strategic Laboratory & Claudio Tavares Sacchi, Claudia Regina Gonçalves, Erica Valessa Ramos Gomes \\
\hline EPI_ISL_471551 & Hospital Sao Paulo de Ensino da Unifesp & Instituto Adolfo Lutz, Interdiciplinary Procedures Center, Strategic Laboratory & Claudio Tavares Sacchi, Claudia Regina Gonçalves, Erica Valessa Ramos Gomes \\
\hline EPI_ISL_471552 & Hospital Sancta Maggiore & Instituto Adolfo Lutz, Interdiciplinary Procedures Center, Strategic Laboratory & Claudio Tavares Sacchi, Claudia Regina Gongalves, Erica Valessa Ramos Gomes \\
\hline EPI_ISL_471554 & Hospital Bosque da Saúde & Instituto Adolfo Lutz, Interdiciplinary Procedures Center, Strategic Laboratory & Claudio Tavares Sacchi, Claudia Regina Gongalves, Erica Valessa Ramos Gomes \\
\hline EPI_ISL_471556 & Pronto Socorro Jose Ibrahin & Instituto Adolfo Lutz, Interdiciplinary Procedures Center, Strategic Laboratory & Claudio Tavares Sacchi, Claudia Regina Gonģalves, Erica Valessa Ramos Gomes \\
\hline 2, EP__SL__471581, EP__SL_-471582 & Hosp. Municipal Prof. Dr. Alípio Corrêa Netto & Instituto Adolfo Lutz, Interdiciplinary Procedures Center, Strategic Laboratory & Claudio Tavares Sacchi, Claudia Regina Gonģalves, Erica Valessa Ramos Gomes \\
\hline EPI_ISL_471647 & Hospital Municipal de Barueri Dr. Francisco Moran & Instituto Adolfo Lutz, Interdiciplinary Procedures Center, Strategic Laboratory & Claudio Tavares Sacchi, Claudia Regina Gonçalves, Erica Valessa Ramos Gomes \\
\hline EPI_ISL_-471648 & UBS e Pronto Socorro Jd. Jacira & Instituto Adolfo Lutz, Interdiciplinary Procedures Center, Strategic Laboratory & Claudio Tavares Sacchi, Claudia Regina Gonçalves, Erica Valessa Ramos Gomes \\
\hline EPI_ISL_476221 & Laboratory Fleury & Instituto de Medicina Tropical da Univesidade de São Paulo & 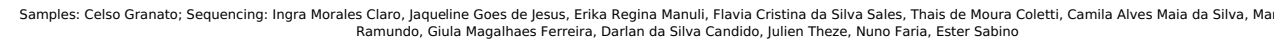 \\
\hline $\begin{array}{l}\text { EPIISL_476288, EPIIS } \\
\text { EPI_IS__476297 }\end{array}$ & DB Diagnósticos do Brasil & Instituto de Medicina Tropical da Univesidade de Săo Paulo & $\begin{array}{l}\text { Samples: Nelson Gaburo Jr; Sequencing: Ingra Morales Claro, Jaqueline Goes de Jesus, Erika Regina Manuli, Flavia Cristina da Silva Sales, Thais de Moura Coletti, Camila Alves Maia da Silva, M. } \\
\text { Ramundo, Gilala Magalhaes Ferreira, Daran da Silva Candido, Julien Theze, Nuno Faria, Ester Sabino }\end{array}$ \\
\hline EPI_ISL_476341 & Laboratório de Patologia Clínica - UNICAMP & Laboratório de Estudos de Virus Emergentes - UNICAMP & $\begin{array}{l}\text { José Luiz Proença-Modena, Magnun Nueldo Nunes dos Santos, Angelica Schreiber, Julia Forato, Camila Simeoni, Marciliij Jorge Fumagalli, Mariene Ribeiro Amorim, Darlan da Silva Candido, Nuu } \\
\text { Faria, Julien Theze, Luiz Gonzaga,Jauuline Goes Jesus e William Marciel de Souzza }\end{array}$ \\
\hline EPI_ISL_476373 & $\begin{array}{l}\text { Hospital da Clinicas da Faculdade de Medicina da Universidade } \\
\text { de Săo Paulo }\end{array}$ & Instituto de Medicina Tropical da Univesidade de Săo Paulo & 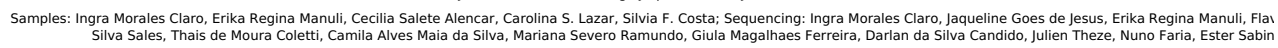 \\
\hline - 476395, EPL_ISL_476398 & Laboratório de Patologia Clínica - UNICAMP & Laboratório de Estudos de Virus Emergentes - UNICAMP & $\begin{array}{l}\text { José Luiz Proença-Modena, Magnun Nueldo Nunes dos Santos, Angelica Schreiber, Julia Forato, Camila Simeoni, Marciliij Jorge Fumagalli, Mariene Ribibiro Amorim, Darlan da Silva Candido, Nuu } \\
\text { Faria, Julien Theze, Luiz Gonzaga, Jauueline Goes Jesus e William Marciel de Souza }\end{array}$ \\
\hline $\begin{array}{l}\text { EPIISL_476439, EPIISL-476445, } \\
\text { EPIISL_476469, EPIISL-476490 }\end{array}$ & $\begin{array}{l}\text { cas da Faculdade de Medicina da Universidade } \\
\text { de Săo Paulo }\end{array}$ & âo Paulo & 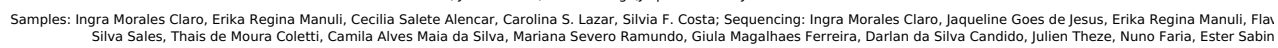 \\
\hline EPI_ISL_483065 & $\begin{array}{l}\text { Centro de Desenvolvimento Tecnologico em Saude, fundacao } \\
\text { Oswaldo Cruz }\end{array}$ & Centro de Desenvolvimento Tecnologico em Saude, Fundacao Oswaldo Cruz & elman-Rodrigues,N., De Paula,A.D., Tschoeke,D., Barroso,S.S.P., Gregorio,M.L., Oliveria,.J.S., Saraiva,F.B., Ferreira,M.M., Sacramento,.C.Q. \\
\hline EPL_ISL_492032 & Instituto de Biologia do Exército & $\begin{array}{l}\text { Laboratatrio Metabolismo Macromolecular FirminoTorres de Castro, Instituto de } \\
\text { Biofisica Carlos Chagas Filho, Universidade Federal do Rio de Janeiro }\end{array}$ & 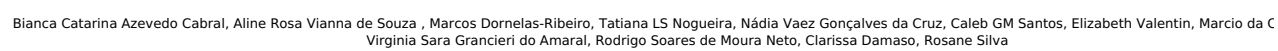 \\
\hline EPI_ISL_492033 & Instituto de Biologia do Exército & $\begin{array}{l}\text { Laboratário Metabolismo Macromolecular FirminoTorres de Castro, Instituto de } \\
\text { Bifísica Carlos Chagas Filho, Universidade Federal do Rio ode laneiro }\end{array}$ & 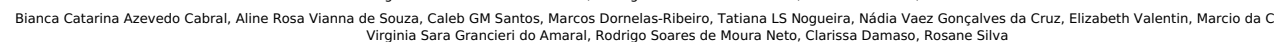 \\
\hline EPI_ISL_492034 & Instituto de Biologia do Exército & 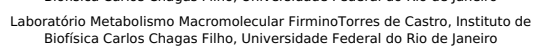 & 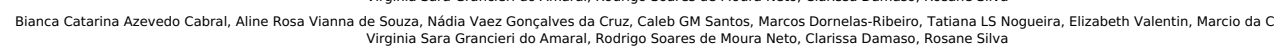 \\
\hline EPI_ISL_492035 & Instituto de Biologia do Exército & 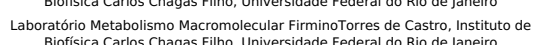 & las-Ribeiro, Elizabeth Valentin, Marcio da c \\
\hline EPI_ISL_492036 & Instituto de Biologia do Exército & 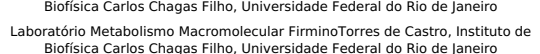 & $\begin{array}{l}\text { va } \\
\text { GM Santos, Elizabeth Valentin, Marcio daC C } \\
\text { va }\end{array}$ \\
\hline EPI_ISL_492037 & Institute & 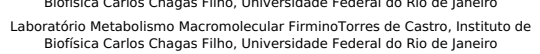 & 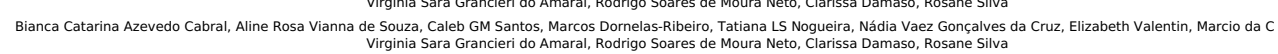 \\
\hline EPL_ISL_492038 & Instituto de Biologia do Exército & 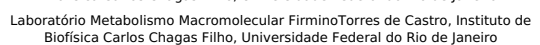 & 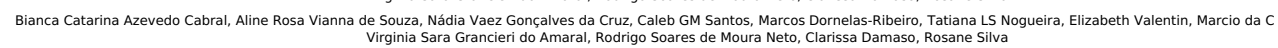 \\
\hline EPI_ISL_492039 & Instituto de Biologia do Exército & 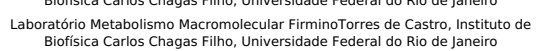 & 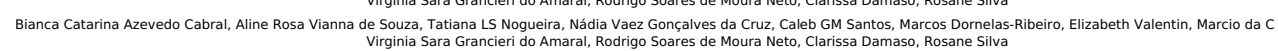 \\
\hline EPP_ISL_492040 & Instituto de Biologia do Exército & 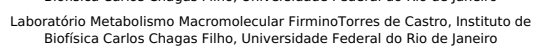 & 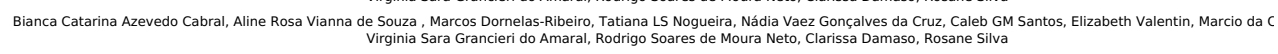 \\
\hline EPP_ISL_492041 & Instituto de Biologia do Exército & $\begin{array}{l}\text { Laboratório Metabolismo Macromolecular Firmino Torres de Castro, Instituto de } \\
\text { Biofíica Carlos Chagas Filiho, Universidade Federal do Rio de Janeiro }\end{array}$ & $\begin{array}{l}\text { Bianca Catarina Azevedo Cabral, Aline Rosa Vianna de Souzza, Caleb GM Santos, Marcos Dornelass-Ribeiro, Tatiana LS Noguueira, Nádia Vaez Goncalves da Cruz, Elizabeth Valentin, Marcio da C } \\
\text { Virginia Sara Grancieri io Amaral, Rodrigo Soares de Moura Neto, Clarissa Damaso, Rosane Silva }\end{array}$ \\
\hline EPI_ISL_492042 & Instituto de Biologia do Exército & $\begin{array}{l}\text { Laboratório Metabolismo Macromolecular FirminoTorres de Castro, Instituto de } \\
\text { Biofísica Carlos chagas Filho, Universidade Federal do Rio de Janeiro }\end{array}$ & 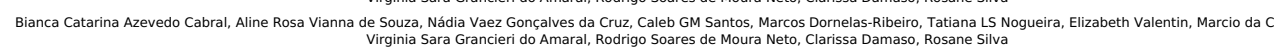 \\
\hline EPIIISL_492043 & Instituto de Bilologia do Exército & $\begin{array}{l}\text { Laboratório Metabolismo Macromolecular Firminoororres de Castro, Instituto de } \\
\text { Biofisica Carlos Chagas Filho, Universidade Federal do Rio de Janeiro }\end{array}$ & 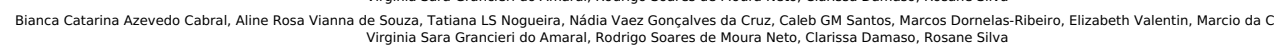 \\
\hline EPI_ISL_492044 & Instituto de Biologia do Exercito & Laboratió & Intos, Elizabeth Valentin, Marcio da c \\
\hline EPL_ISL_492045 & Instituto de Biologia do Exército & $\begin{array}{l}\text { cular Firmino Torres de castro, Instituto de } \\
\text { civersidade Federal do Rio de enaniro }\end{array}$ & $\begin{array}{l}\text { Silva } \\
\text { Ives da Cruz, Elizabeth Valentin, Marcio da C } \\
\text { silia }\end{array}$ \\
\hline EPI_ISL_492046 & Instituto de Biologia do Exércitc & $\begin{array}{c}\text { Bir } \\
\text { Labora } \\
\text { Bit }\end{array}$ & Nogueira, Elizabeth Valentin, Marcio da C \\
\hline EPI_ISL_492047 & Instituto de Biologia do Exército & $\begin{array}{l}\text { Biofisica Carlos Chagas Filho, } \\
\text { Laboratório Metabolismo Macromo } \\
\text { Bifofisica carlos Chagas s ifhho }\end{array}$ & vas-ibeiro, Elizabeth Valentin, Marcio da C \\
\hline EPI_ISL_492048 & רstituto de Biologia do Exército & 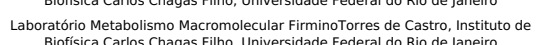 & in Santos, Elizabeth Valentin, Marcio da $C$ \\
\hline
\end{tabular}

